\title{
Tumor necrosis factor- $\alpha$ from resident lung cells is a key initiating factor in pulmonary ischemia-reperfusion injury
}

\author{
Thomas S. Maxey, MD \\ Richard I. Enelow, $M D^{b}$ \\ Benjamin Gaston, $\mathrm{MD}^{\mathrm{C}}$ \\ Irving L. Kron, $\mathrm{MD}^{\mathrm{a}}$ \\ Victor E. Laubach, $\mathrm{PhD}^{\mathrm{a}}$ \\ Allan Doctor, MD ${ }^{d}$
}

From the Division of Thoracic and Cardiovascular Surgery, ${ }^{a}$ Pulmonary Medicine, ${ }^{\mathrm{b}}$ Pediatric Pulmonary Medicine, ${ }^{c}$ and Pediatric Critical Care, ${ }^{\mathrm{d}}$ University of Virginia Health System, Charlottesville, Va.

Read at the Eighty-third Annual Meeting of The American Association for Thoracic Surgery, Boston, Mass, May 4-7, 2003.

This research was supported by 5 RO1 HL069170-03, Asthma Center POIAI50989-03, and 2 RO1 HL056093-05A2.

Received for publication May 2, 2003; revisions requested Aug 25, 2003; accepted for publication Sept 9, 2003.

Address for reprints: Victor E. Laubach, $\mathrm{PhD}$, University of Virginia, Thoracic and Cardiovascular Surgery, PO Box 801359, Charlottesville, VA 22908 (E-mail: vel8n@virginia.edu).

J Thorac Cardiovasc Surg 2004;127:541-7 $0022-5223 / \$ 30.00$

Copyright $\odot 2004$ by The American Association for Thoracic Surgery

doi:10.1016/j.jtcvs.2003.09.008
Objective: A central role of macrophages in initiating lung ischemia-reperfusion injury is emerging. Tumor necrosis factor- $\alpha$ is a proinflammatory cytokine secreted mainly by macrophages under various conditions. We hypothesized that tumor necrosis factor- $\alpha$ from resident lung cells is a key initiating factor in pulmonary ischemia-reperfusion injury.

Methods: We used an isolated, buffer-perfused lung system to explore the role of tumor necrosis factor- $\alpha$ production by resident lung cells in pulmonary ischemiareperfusion injury. Lungs from wild-type mice and tumor necrosis factor- $\alpha$-deficient mice were subjected to 60 minutes of ischemia followed by 60 minutes of reperfusion. Histologic injury scores and measurements of lung compliance, airway resistance, mean pulmonary artery pressure, vascular reactivity, and wet lung weight index were obtained and compared using repeated-measures analysis of variance.

Results: Lungs from tumor necrosis factor- $\alpha$-deficient mice showed significantly less injury in all physiologic parameters throughout the entire 60 minutes of reperfusion compared with lungs from wild-type mice $(P<.001)$. The most notable effects were observed in pulmonary artery pressure and airway resistance. Vascular reactivity (acute vasoconstrictive episodes per 60 minutes) was also blunted in the lungs from tumor necrosis factor- $\alpha$-deficient mice compared with the lungs from wild-type mice (5.8 responses/hour vs 1.2 responses). Histologic injury scores and wet lung weight index were significantly reduced in lungs from tumor necrosis factor- $\alpha$-deficient mice.

Conclusions: By using the advantages of a nonblood-perfused system, we have focused our investigation on resident lung cells. Our results demonstrate that resident cell-produced tumor necrosis factor- $\alpha$ is a key initiating factor in acute lung ischemia-reperfusion injury.

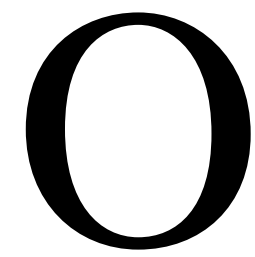

ur group and others have demonstrated that lung ischemia-reperfusion (I/R) injury is complex and that it involves many systems, for example, the release of oxygen radicals, xanthine-oxidase system, leukocyte adhesion and rolling factors, and activation of neutrophils and alveolar macrophages. ${ }^{1-6}$ The complement system has also been implicated, in which both the formation of membrane attach complex and generation of the anaphylatoxin C5a can contribute to I/R injury. ${ }^{7}$ There is increasing evidence indicating that tumor necrosis factor (TNF)- $\alpha$ is an initiating factor in many of these processes and is required to produce the pathophysiology in lungs subjected to different inflammatory models and endotoxin shock. $^{8-10}$ 
TNF- $\alpha$ is a $17-\mathrm{kDa}$ proinflammatory cytokine predominantly secreted by macrophages in response to a variety of pathologic processes. Investigators have demonstrated that TNF- $\alpha$ compromises the endothelial barrier and produces experimental pulmonary edema. ${ }^{11,12}$ TNF- $\alpha$, as well as other proinflammatory cytokines, has been detected in the bronchoalveolar lavage fluid obtained from patients with acute respiratory distress syndrome ${ }^{13}$ and has been shown to increase pulmonary vascular resistance, resulting in alveolar edema because of the release of thromboxane A2 in response to activation of polymorphonuclear leukocytes. ${ }^{12}$ TNF- $\alpha$ also increases the neutrophil population in the lung caused by inducing endothelium-derived polymorphonuclear chemotactic and adherent factors. ${ }^{14}$

TNF- $\alpha$ may function as the initial cytokine in the complex inflammatory cascade observed in lung $\mathrm{I} / \mathrm{R}$ injury. Previous studies have been unable to completely isolate specific components of pulmonary I/R injury; thus it has been difficult to focus on single components of this complex cascade. The main objective of this project was to investigate the role of resident lung cells (most likely macrophages) and TNF- $\alpha$ secreted by these cells in pulmonary I/R injury. Our hypothesis is that TNF- $\alpha$ from resident lung cells is a key initiating factor in pulmonary $\mathrm{I} / \mathrm{R}$ injury.

\section{Methods}

\section{Study Design}

By use of an isolated lung system, lungs from male wild-type (WT) C57BL6 mice $(\mathrm{n}=8)$ and male mice deficient in the TNF- $\alpha$ gene $(\mathrm{TNF}-/-)(\mathrm{n}=8)$ were subjected to 60 minutes of pulmonary ischemia followed by 60 minutes of reperfusion with KrebsHenseleit buffer. As a control, the WT sham group received 120 minutes of reperfusion without ischemia. To minimize any inherent variability between groups, the animals used in all groups (25-30 g body weight) were born within the same week and housed in the same vivarium. Hemodynamic and pulmonary parameters, as well as histologic grading scores, were compared between the 2 groups throughout the reperfusion period.

Animal acquisition was under the supervision of the Department of Comparative Medicine and a licensed veterinarian. All animals received humane care in compliance with the "Principles of Laboratory Animal Care," formulated by the National Society for Medical Research, and "The Guide for the Care and Use of Laboratory Animals," prepared by the National Academy of Science and published by the National Institutes of Health (publication 85-23, revised 1985).

\section{Isolated, Perfused Lung Model}

For this study, we used an isolated, perfused mouse lung system (Hugo Sachs Elektronik, March-Huggstetten, Germany). Mice were anesthetized with ketamine and xylazine. A tracheostomy was performed, and animals were ventilated with room air at 100 breaths $/ \mathrm{min}$ and a tidal volume of $15 \mathrm{~mL} / \mathrm{kg}$ body weight with a positive end-expiratory pressure of $2 \mathrm{~cm} \mathrm{H}_{2} \mathrm{O}$. A midline abdominal incision was made, and the inferior vena cava was cannulated with a $30 \mathrm{G}$ needle and injected with 50 units of heparin. The animals were exsanguinated by inferior caval transection. The subdiaphragmatic portion of the animal was excised and discarded. The anterior chest plate was removed, exposing the lungs and heart. With the use of an operating microscope, the thymus was dissected cephalad exposing the great vessels. A 4-0 silk suture was passed behind the pulmonary artery (PA) and aortic root. A partial half-knot was created with the suture, leaving room for a cannula to be passed into the PA. A small curvilinear incision was made in the right ventricular outflow tract with the perfusate flowing at $0.6 \mathrm{~mL} / \mathrm{min}$, and the PA cannula was passed under direct vision through the pulmonary valve and into the main PA. The left ventricle was immediately vented with a small incision at the apex of the heart. The mitral apparatus was carefully dilated, and the left atrial cannula was passed through the mitral valve and into the left atrium. The placement of the PA and left atrial cannula was further confirmed by a pressure tracing generated by the PULMODYN data acquisition system (Hugo Sachs Elektronik). The lungs were then perfused at a constant flow of $2 \mathrm{~mL} / \mathrm{min}$ with Krebs-Henseleit buffer containing $2 \%$ albumin, $0.1 \%$ glucose, and 0.3\% HEPES (335-340 mOsm/kg). The Krebs solution was prepared to mimic mixed venous blood using a gas bubbling stone with titrated gases generating a $\mathrm{pH}$ of 7.40 to $7.45, \mathrm{a} \mathrm{Po}_{2}$ of 60 to $70 \mathrm{~mm} \mathrm{Hg}$, and a $\mathrm{PCO}_{2}$ of 50 to $60 \mathrm{~mm} \mathrm{Hg}$. The buffered perfusate and isolated lung apparatus were maintained at $37^{\circ} \mathrm{C}$.

All lungs were allowed to equilibrate during a 10-minute stabilization period. After equilibration, the ventilation rate was decreased to 50 breaths/min, and the fraction of inspired oxygen was decreased to less than $1 \%$. To initiate the ischemic period, hypoxic ventilation was maintained with $95 \%$ nitrogen and $5 \%$ carbon dioxide gas, and perfusion was arrested. After 60 minutes of ischemia and hypoxic ventilation, the perfusion and room air ventilation were resumed, initiating the reperfusion period. Left atrial efflux was collected at 1-minute intervals for the first 5 minutes of reperfusion and then every 15 minutes thereafter for the entire 1-hour period of reperfusion.

\section{Hemodynamic and Pulmonary Parameters}

PA pressure (PAP), pulmonary venous (left atrial) pressure, airway resistance (AR), peak airway pressure, and pulmonary compliance were continuously measured, recorded, and stored by the PULMODYN W software system (Hugo Sachs Elektronik). All of the system's transducers were designed and selected specifically for the parameters to be measured. For measurement of vascular pressures, a transducer with a limited pressure range (P75; pressure range $\pm 75 \mathrm{~mm} \mathrm{Hg}$ ) was used to obtain sensitive and accurate measurement of venous pressures. A separate low-pressure transducer (pressure range $\pm 100 \mathrm{~cm} \mathrm{H}_{2} \mathrm{O}$ ) was used to measure air pressures within the airway (using an optional pneumotachometer with a pressure side port). The integrated pneumotachometer and matched differential pressure transducer were designed specifically to measure respiratory airflow from the mouse lung. AR (dynamic resistance) is defined as "delta pressure" divided by "delta flow." To calculate resistance, PULMODYN takes the corresponding pleural pressure (or esophageal pressure) values and pulmonary flow values at $70 \%$ of the amplitude in the tidal volume signal to calculate the "delta pressure" and "delta flow." Pulmonary compliance is defined as "delta volume" divided by "delta 


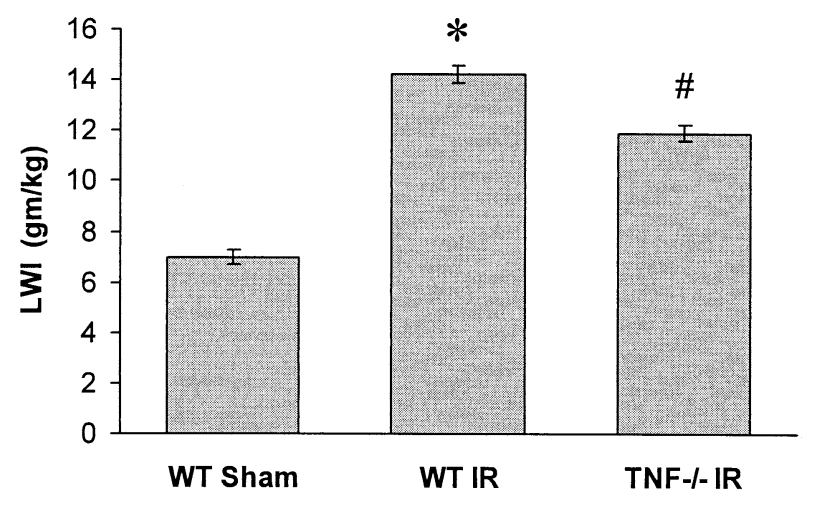

Figure 1. LWI after reperfusion $\left({ }^{*} P<.05\right.$ vs all, $\# P<.05$ vs WT sham). WT, Wild-type; TNF-/-, tumor necrosis factor- $\alpha$ deficient; $I / R$, ischemia-reperfusion; $L W I$, lung weight index.

pressure." To calculate compliance, PULMODYN takes the corresponding tidal volume values and pleural pressure values (or esophageal pressures) at the zero points of the flow signal to calculate the "delta volume" and "delta pressure."

\section{Lung Weight Index}

At the completion of reperfusion, the mediastinal structures were removed en bloc, and the lungs were individually weighed. This weight was then divided by the preprocedure weight of the mouse to obtain the lung weight index (LWI).

\section{Lung Injury Score}

After the lung weight was obtained, the right lower lobe was fixed in $10 \%$ buffered formalin and embedded in paraffin. Slides were stained with hematoxylin-eosin and examined by a pulmonary pathologist blinded to animal group. Lung tissue was graded by the presence or absence of interstitial infiltrate, intra-alveolar fibrin, and alveolar integrity, providing a total injury score of 0 to $3(0=$ no injury, 3 = severely injured).

\section{Statistical Analysis}

Data are presented as mean \pm SEM. Analysis of variance (ANOVA) was used to determine whether significant differences existed between groups. Two-way repeated-measures ANOVA was used to compare pulmonary and hemodynamic trends during the reperfusion period.

\section{Results}

\section{Pulmonary Edema}

The detrimental effects of TNF- $\alpha$ were clearly exhibited in every parameter measured during reperfusion. The most notable differences were those relating to pulmonary edema. Severe edema resulted in the failure to complete 60 minutes of reperfusion in $4 \mathrm{WT}$ animals exposed to I/R (not included in the study) because the perfusate was pulled into the ventilator, forcing termination of the experiment. This observation was not observed in $\mathrm{TNF}-/-$ mice.

Figure 1 shows the increased endothelial leakage and subsequent pulmonary edema observed after I/R. Although individual lung weights were always greater in the right lung than the left, the relationship remained consistent. The LWI after I/R was $19.3 \%$ greater in the WT lungs (14.2 \pm $0.3)$ compared with the TNF-/- lungs $(11.9 \pm 0.3, P<$ $.05)$. Again, this was very notable at the gross level because the WT lungs subjected to I/R frequently leaked perfusate during the reperfusion period. The LWIs in both WT and TNF-/- lungs subjected to I/R were significantly higher than in the WT sham lungs subjected to the same perfusion protocol without ischemia.

\section{Mean PAP}

Mean PAP was significantly reduced in TNF-/- lungs subjected to I/R throughout the reperfusion period (Figure 2) compared with WT lungs subjected to I/R. Interestingly, this difference was noted at the onset of reperfusion when the WT lungs subjected to I/R were profoundly hypertensive immediately on reperfusion. PAP in all groups, before ischemia, was not different, ranging from 8 to $10 \mathrm{~cm} \mathrm{H}_{2} \mathrm{O}$. Subtle increases in mean PAP were observed in the $\mathrm{TNF}-/$ - lungs after 40 minutes, but these did not reach even half the increases seen in the WT lungs subjected to $\mathrm{I} / \mathrm{R}$. The cumulative effect observed in the PAP tracing is the result of acute vasoconstrictive responses observed throughout the 60-minute reperfusion period. These hypertensive spikes were observed frequently in the WT lungs subjected to I/R (5.8 responses/hour) versus the TNF-/lungs subjected to I/R (1.2 responses/hour), with PAP increasing 2-fold for periods of 1 to 3 minutes before a return to baseline. These vascular response spikes resembled those seen in hypoxic pulmonary vasoconstrictive models, yet there was no hypoxia during the reperfusion period when these episodes were observed.

\section{AR}

AR, unlike PAP, was similar between all groups at the initial stage of reperfusion, ranging from 0.8 to $0.9 \mathrm{~cm} \mathrm{H}_{2} \mathrm{O}$ - $\mu \mathrm{L} \cdot \sec$ (Figure 3). At 30 minutes of reperfusion, an approximate doubling of AR was observed in the WT lungs subjected to I/R, and at 60 minutes the AR was 4 times greater in the WT lungs subjected to I/R compared with the TNF $-/-$ lungs subjected to $\mathrm{I} / \mathrm{R}(P<.05)$. This finding may indicate the effects of TNF- $\alpha$ extending beyond the level of the pulmonary vasculature to that of the bronchial epithelium, causing bronchoconstriction.

\section{Pulmonary Compliance}

Pulmonary compliance is one of the most significant clinical indicators of reperfusion injury. Figure 4 illustrates the change in pulmonary compliance observed during reperfusion. The TNF-/- lungs subjected to I/R demonstrated significantly improved compliance throughout the entire 


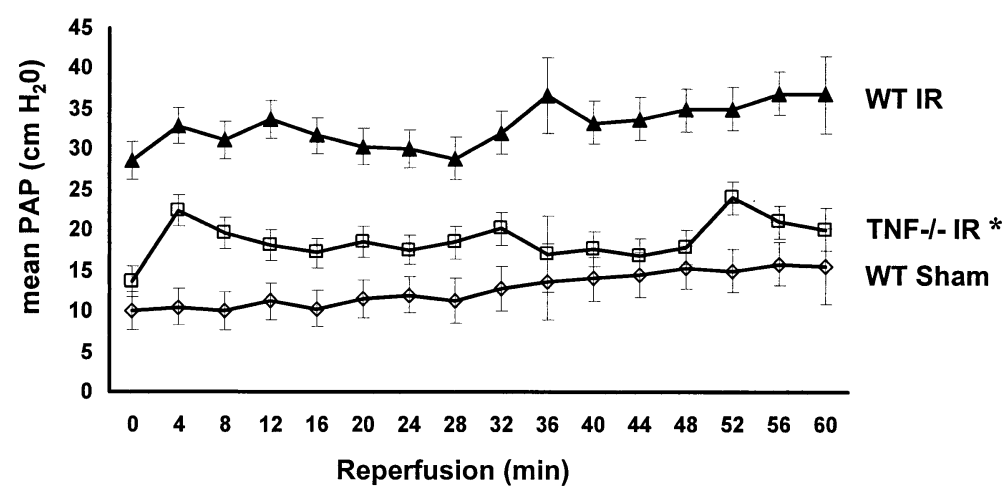

Figure 2. Mean PAP during 60 minutes of reperfusion (*P $<.05$ using 2-way repeated-measures ANOVA). WT, Wild-type; $T N F-/-$, tumor necrosis factor- $\alpha$ deficient; $I / R$, ischemia-reperfusion; PAP, pulmonary artery pressure.

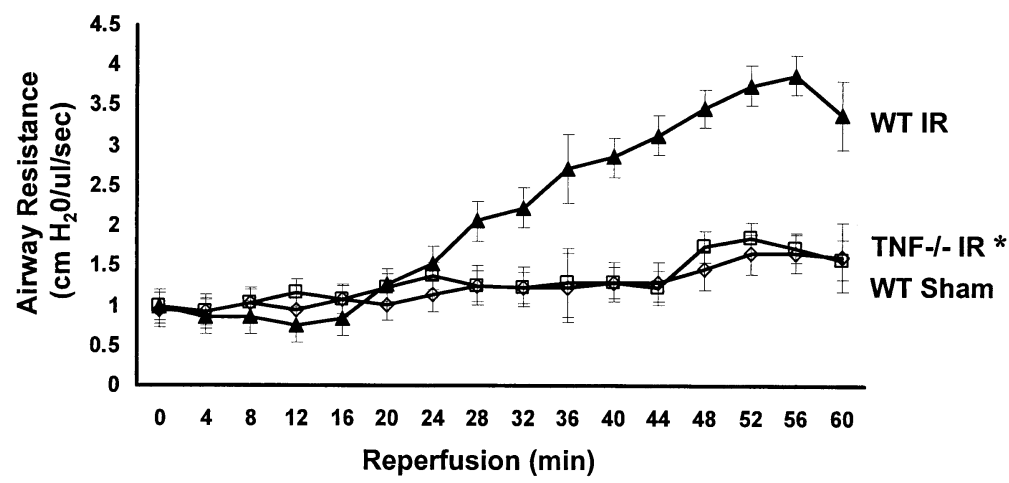

Figure 3. AR during 60 minutes of reperfusion $(* P<.05$ using 2-way repeated-measures ANOVA). WT, Wild-type; $T N F-/-$, tumor necrosis factor- $\alpha$ deficient; $I / R$, ischemia-reperfusion.

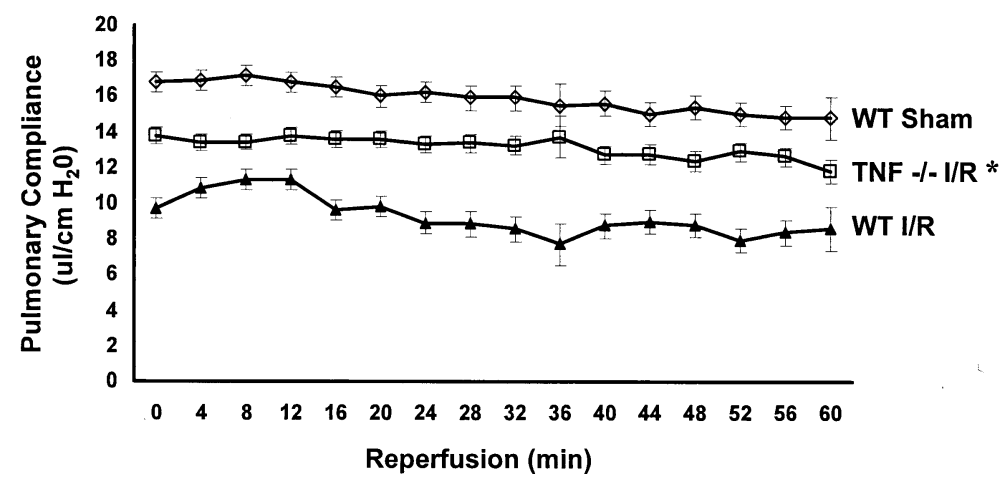

Figure 4. Pulmonary compliance during 60 minutes of reperfusion $\left({ }^{*} P<.05\right.$ using 2-way repeated-measures ANOVA). WT, Wild-type; TNF-/-, tumor necrosis factor- $\alpha$ deficient; $I / R$, ischemia-reperfusion.

reperfusion period compared with the WT lungs subjected to I/R. The WT lungs subjected to I/R, however, demonstrated diminished compliance as early as 20 minutes, and at 50 minutes compliance was $38 \%$ less than in the TNF-/lungs subjected to I/R. Pulmonary compliance in all groups, before ischemia, was not different, ranging from 21 to 24 $\mu \mathrm{L} / \mathrm{cm} \mathrm{H}_{2} \mathrm{O}$.
Histologic Grading of Lung Injury

Table 1 illustrates the histologic grading of pulmonary injury after 60 minutes of reperfusion. The WT lungs exposed to $\mathrm{I} / \mathrm{R}$ demonstrated a more than double histologic injury score $(2.00 \pm 0.17)$ compared with the TNF-/lungs exposed to I/R $(0.86 \pm 0.26, P<.001)$. Notably, the TNF $-/-$ lungs demonstrated no more significant injury 
than that observed in the WT sham lungs subjected to perfusion but no ischemia.

\section{Discussion}

The multifaceted phenomenon of I/R involves many components, including alveolar macrophages, vascular endothelial cells, circulating neutrophils, adhesion factors, free radicals, complement, and a wealth of cytokines such as TNF- $\alpha$. Our group and others have attempted to better understand and describe some of the components of this process. The complexity and amplification of the cascades involved in this phenomenon, however, have made investigation of individual components of reperfusion injury difficult to assess.

There is a large body of literature describing techniques to attenuate lung $\mathrm{I} / \mathrm{R}$ injury; however, little attention is focused on the specific mechanisms of lung I/R injury itself. In particular, characterization of the injury pattern during the early phase of reperfusion is very limited. Our group has recently described the biphasic nature of reperfusion injury after lung transplantation, beginning with a resident (donor) macrophage response followed by a more intense response by circulating (recipient) neutrophils. ${ }^{3}$

Neutrophils have long been recognized as a critical component of the inflammatory cascade, yet their role in lung $\mathrm{I} / \mathrm{R}$ injury has been a source of controversy. Evidence that circulating neutrophils play an important role in lung $\mathrm{I} / \mathrm{R}$ injury has been suggested by investigators using leukocyte depletion techniques and antibodies directed toward adhesion molecules. ${ }^{1,9,15}$ In contrast, some investigators have demonstrated that significant I/R injury can occur without neutrophil participation and that neutrophils may have no effect at all in some models of lung injury. ${ }^{16}$ Because of the discrepancies regarding the role of neutrophils in lung $I / R$ injury, we used a model that eliminated the role of circulating neutrophils altogether and that allowed us to focus strictly on resident cells in the lung.

The goal of this project was to establish a working model of lung I/R in a nonblood-perfused system. We developed a novel technique of evaluating $\mathrm{I} / \mathrm{R}$ in an isolated murine lung system and investigated its unique advantages using oxygenated buffer (not blood) during reperfusion. The advantages of this system are 3-fold: (1) A pH-balanced, buffered solution completely eliminates the roll of circulating cells in the acute response of reperfusion injury; (2) a nonbloodperfused system eliminates the need for large quantities of blood to prime the reperfusion pump; and (3), most important, this system allows us to explore more in-depth cellular and molecular mechanisms by using various genetic mouse models.

The oxygen supply to cells and tissues is pivotal in maintaining their function and integrity. I/R injury, however, is not totally dependent on ischemic time. I/R injury is
TABLE 1. Histologic lung injury score after reperfusion

\begin{tabular}{lc}
\hline Group & Lung injury score* \\
\hline WT sham & $0.67 \pm 0.21$ \\
WT I/R & $2.00 \pm 0.17 \dagger$ \\
TNF-/-I/R & $0.86 \pm 0.26$ \\
\hline
\end{tabular}

$W T$, Wild-type; TNF-/-, tumor necrosis factor- $\alpha$ gene knockout mice; $I / R$, ischemia-reperfusion.

${ }^{*}$ Scale: $0=$ no injury, $3=$ severely injured.

$\dagger P<.001$ versus all.

a paradoxical increase in tissue injury during the reperfusion period in an organ that has sustained relatively minor damage during a period of ischemia. ${ }^{17}$ Atochina and colleagues ${ }^{18}$ have convincingly demonstrated that pulmonary tissue oxygenation can occur through pulmonary vasculature or alveolar oxygen diffusion. Lung ischemia does not necessarily lead to tissue anoxia, and reperfusion does not mean reoxygenation if ventilation is maintained throughout the ischemic period. Clinically, this principal is applied during cardiopulmonary bypass to avoid reperfusion injury because ventilation of the pulmonary tissue is maintained despite cardiopulmonary arrest. In the present study, we used an isolated murine lung system ventilated with 95\% nitrogen and 5\% carbon dioxide during the ischemic period. The technique of constant ventilation with hypoxic gas allowed us to avoid the possible effects of reoxygenation injury associated with atelectatic lung tissue and instead focus on reperfusion injury.

Serrano and colleagues ${ }^{19}$ showed that TNF- $\alpha$ enhances intercellular adhesion molecule-1, E-selectin, and vascular cell adhesion molecule-1 expression in human aortic endothelial cell monolayers. Ferro and colleagues ${ }^{20}$ showed that a 4-hour incubation with TNF- $\alpha$ reduces PA endothelial monolayer selectivity by a nitric oxide-dependent mechanism. However, the studies that evaluate cytokine involvement in producing lung damage usually require 3 to 4 hours before the endothelial barrier damage is present in measurable amounts. Even when TNF- $\alpha$ is administered to animals or placed into bathing solutions surrounding endothelial cell monolayers, 3 to 4 hours are required before monolayer damage and the cell up-regulation of adhesion and rolling factors occur. ${ }^{13,18}$ Previous studies with I/R models of isolated rat lungs used much shorter periods of ischemia (45 minutes-1 hour) followed by 1 to 2 hours of reperfusion. Eppinger and colleagues ${ }^{9}$ recently published data demonstrating an increase in TNF- $\alpha$ mRNA expression in rat lungs subjected to 1.5 hours of ischemia and only 30 minutes of reperfusion. From these data, we hypothesized that TNF- $\alpha$ is involved in even the most acute stages of pulmonary reperfusion injury.

Leukocyte trafficking into sites of inflammation is largely directed by cytokines. The presence of cytokine gene expression or protein during I/R injury has been shown 
in several model systems. ${ }^{9}$ The role of specific cytokines such as TNF- $\alpha$ in mediating leukocyte populations in lungs subjected to I/R has not been defined. The role that TNF- $\alpha$ plays in $\mathrm{I} / \mathrm{R}$ injury in the present study is unique from other published data. We propose that the effect of TNF- $\alpha$ in pulmonary $\mathrm{I} / \mathrm{R}$ injury is beyond neutrophil recruitment into previously ischemic tissue. Our isolated, nonblood-perfused model has demonstrated a direct negative effect on pulmonary vascular endothelium and alveolar wall structure without any participation from circulating cells.

Although the pathophysiology of $\mathrm{I} / \mathrm{R}$ injury in the lung is not completely understood, loss of normal endothelial function and integrity seems to play a pivotal role. ${ }^{21}$ Our use of a blinded pulmonary pathologist in attaining lung injury scores provided interesting results. The scoring system our group previously used for quantifying lung injury ${ }^{22}$ required modification in this study because of the lack of neutrophil infiltration that would normally be observed in injured or reperfused lung tissue. Light microscopy demonstrated diminished perivascular edema and alveolar destruction in $\mathrm{TNF}-/-$ lungs exposed to anoxic ventilation followed by reperfusion and oxygenation compared with the same insult on WT lungs. This histologic finding was grossly manifested in lung weight indices and physiologically characterized by decreased pulmonary compliance and increased mean airway pressures in WT lungs subjected to I/R compared with TNF-/- lungs exposed to I/R.

Vascular endothelium is a predominant cellular source of oxidants associated with lung I/R injury. The role of resident lung cells such as macrophages, however, is not fully understood and may have a more predominant role than previously believed in lung $I / R$ injury. Macrophages are pivotal cells in the production of a variety of cytokines, especially TNF- $\alpha$. In addition, macrophages express receptors on their surface, which allows them to act as target cells for cytokines.

We used novel technology in the investigation of pulmonary I/R injury. Our study demonstrates the application of an isolated, nonblood-perfused murine system to investigate very specific components of a complex physiologic process. Our data demonstrate that TNF- $\alpha$ from resident lung cells is a key initiating factor in pulmonary $\mathrm{I} / \mathrm{R}$ injury. The source of this TNF- $\alpha$ has not been established, but it may likely arise from resident lung macrophages. These findings have important clinical implications in areas of lung transplantation and cardiopulmonary bypass surgery. For example, these results indicate that anti-TNF- $\alpha$ therapy directly to the donor lung before transplantation may significantly blunt the initiation of acute I/R injury that is observed in many patients posttransplantation.

We express our appreciation to Dr Mark Stoler for histologic evaluation of lung sections and to Kim Shockey for statistical analysis.

\section{References}

1. Ross SD, Tribble CG, Gaughen JR, Shockey KS, Parrino PE, Kron IL. Reduced neutrophil infiltration protects against lung reperfusion injury after transplantation. Ann Thorac Surg. 1999;67:1428-34.

2. Ross SD, Kron IL, Gangemi JJ, Shockey KS, Stoler M, Kern JA, et al. Attenuation of lung reperfusion injury after transplantation using an inhibitor of nuclear factor- $\kappa$ B. Am J Physiol. 2000;279:L528-36.

3. Fiser SM, Tribble CG, Long SM, Kaza AK, Cope JT, Laubach VE, et al. Lung transplant reperfusion injury involves pulmonary macrophages and circulating leukocytes in a biphasic response. $J$ Thorac Cardiovasc Surg. 2001;121:1069-75.

4. Adkins WK, Taylor AE. Role of xanthine oxidase and neutrophils in ischemia-reperfusion injury in rabbit lung. J Appl Physiol. 1990;69: 2012-8.

5. Allison RC, Adkins WK, Prasad VR, Grisham MB, McCord JM, Taylor AE. Effect of ischemia/reperfusion or hypoxia/reoxygenation on lung vascular permeability and resistance. J Appl Physiol. 1990; 69:597-603.

6. Moore TM, Khimenko PL, Adkins WK, Miyasaka M, Taylor AE. Adhesion molecules contribute to ischemia and reperfusion-induced injury in isolated rat lung. $J$ Appl Physiol. 1995;78:2245-52.

7. Riedemann NC, Ward PA. Complement in ischemia reperfusion injury. Am J Pathol. 2003;162:363-7.

8. Bagby GJ, Plessala KJ, Wilson LA, Thompson JJ, Nelson S. Divergent efficacy of antibody to tumor necrosis factor- $\alpha$ in intravascular and peritonitis models of sepsis. J Infect Dis. 1991;163:83-8.

9. Eppinger MJ, Deeb GM, Bolling SF, Ward PA. Mediators of ischemiareperfusion injury of rat lung. Am J Pathol. 1997;150:1773-84.

10. Barnes PJ. Cytokines as mediators of chronic asthma. Am J Respir Crit Care Med. 1994;150:S42-9.

11. Koga S, Morris S, Ogawa S, Liao H, Bilezikian JP, Chen G, et al. TNF modulates endothelial properties by decreasing cAMP. Am J Physiol. 1995;268:C1104-13.

12. Hocking DC, Phillips PG, Ferro TJ, Johnson A. Mechanism of pulmonary edema induced by tumor necrosis factor- $\alpha$. Circ Res. 1990; 67:68-77.

13. Strieter RM, Kunkel SL, Showell HJ, Remick DG, Phan SH, Ward PA, et al. Endothelial cell expression of a neutrophil chemotactic factor by TNF-alpha, LPS, and IL-1-beta. Science. 1989;243:1467-9.

14. Bevilacqua MJ, Prober J, Mendrick D, Cotran R, Gimbrone M. Identification of an inducible endothelial-leukocyte adhesion molecule. Proc Natl Acad Sci U S A. 1987;84:9238-42.

15. Breda MA, Hall TS, Stuart S, Baumgartner WA, Borkon AM, Brawn $\mathrm{JD}$, et al. Twenty-four hour lung preservation by hypothermia and leukocyte depletion. J Heart Transplant. 1985;4:325-9.

16. Steimle CN, Guynn TP, Morganroth ML, Bolling SF, Carr K, Deeb GM. Neutrophils are not necessary for ischemia reperfusion injury of the lung. Ann Thorac Surg. 1992;53:64-73.

17. McCord JM. Oxygen-derived free radicals in postischemic tissue injury. N Engl J Med. 1985;312:159-63.

18. Atochina EN, Muzykantov VR, Al-Mehdi AB, Danilov SM, Fisher AB. Normoxic lung ischemia reperfusion accelerates shedding of angiotensin converting enzyme from the pulmonary endothelium. Am J Respir Crit Care Med. 1997;156:1114-9.

19. Serrano CV Jr, Fraticell AI, Paniccia R, Teti A, Noble B, Corda S, et al. $\mathrm{pH}$ dependence of neutrophil-endothelial cell adhesion and adhesion molecule expression. Am J Physiol. 1996;271:C962-70.

20. Ferro TJ, Gertzberg N, Selden L, Neumann P, Johnson A. Endothelial barrier dysfunction and $\mathrm{p} 42$ oxidation induced by TNF- $\alpha$ are mediated by nitric oxide. Am J Physiol. 1997;272:L979-88.

21. Hunter DN, Morgan CJ, Yacoub M, Evans TW. Pulmonary endothelial permeability following lung transplantation. Chest. 1992;102:417-21.

22. Claridge JA, Weed AC, Enelow R, Young JS. Laparotomy potentiates cytokine release and impairs pulmonary function after hemorrhage and resuscitation in mice. $J$ Trauma. 2001;50:244-52.

\section{Discussion}

Dr G. Alexander Patterson (St Louis, Mo). Does this model use a 1-hour period of ischemia? 
Dr Maxey. That is correct. We begin with a 10-minute stabilization period after hemorrhage in which the buffer is simply perfused through the pulmonary circuit. To begin the experiment, the lungs are no longer perfused, the buffer is simply turned off, and I control the ventilatory status and can make them hypoxic or normoxic.

Dr Patterson. I would like your comments about this. One of the problems with all these reperfusion studies or I/R injury studies is the model. Is the model too extreme? You showed some differences, but there were some areas in which there really was not a whole lot of difference. Is the model too severe to answer the question that you pose? Do you have any data from a shorter period of ischemia?

Dr Maxey. We are currently working on a methods article to describe this new technique. This is a novel technique, and we are one of the first groups using this model. We do have some data. If I can have my slides to further demonstrate the model.

(Slide) Nitrotyrosine staining. This is a stain that is fairly nonspecific but is a marker of oxidative injury. One slide shows the sham animals that did not undergo an ischemic period before the perfusion. The other slide demonstrates marked oxidative injury of the endothelium. So the injury we are seeing is oxidative in nature, consistent with reperfusion, but we are currently working on a grading system that will more accurately define the injury after 15 and 30 minutes of ischemia.

Dr Jakob Vinten-Johansen (Atlanta, $G a$ ). That is a very nice study. How did you ascertain that the TNF- $\alpha$ was in fact derived from macrophages because tissue itself can release inflammatory mediators?

Have you used, for example, an antagonist or receptor type-1 to double-check the role of TNF- $\alpha$ ?

What is the connection between TNF- $\alpha$ and oxidant-mediated injury in a cell-free environment such as this?

Dr Maxey. Those are certainly very good and important questions, especially for a new model.

The TNF- $\alpha$ oxidant injury that I think we are seeing for this particular model is related to the effects of TNF weakening the endothelium. With a weakened endothelial barrier, most of the results that we have seen are probably related to pulmonary edema.
We are currently investigating the peripheral effects of TNF, particularly its role in bronchoconstriction. I believe the damage observed in this model is TNF mediated and results in endothelial destruction and then pulmonary edema.

As far as studies using antibodies or blockers to further define the role of TNF, this model does have some limitations. This new technique involves an asanguinous model. If we pretreat the animals with a TNF antibody and then the animals are exsanguinated, the role of that particular antibody would be difficult to correctly define.

On the other hand, we can take the antibody and put it in the buffer and perfuse the pulmonary circuit with this antibody, but again, I am not sure the buffer and antibody would reach the interstitial macrophages. We are, however, currently working on methods to better define this particular model. We have recently used macrophage inhibitors with hopes to mimic these results as well.

As far as the TNF-macrophage connection, true, other cells do secrete TNF- $\alpha$, but they are mostly circulating cells, and again, we have eliminated the role of circulating cells in this particular model. So whatever is making TNF (we will assume that it is the resident macrophages for the purpose of this study), it is certainly present in the lung tissue. Again, this model involves no circulatory cells whatsoever. So the resident cells within the lung, particularly pulmonary macrophages, are the main secretors of TNF.

Dr Frank W. Sellke (Boston, Mass). I will go back to that point. In the heart and other organs, parenchymal tissue actually produces most of the TNF. You can perform immunohistochemistry to determine the actual location of TNF in your model. Also, have you looked at other cytokines, for example, interleukin (IL)-2 and IL-6, to see if you see the same effects or is this specific for TNF- $\alpha$ ?

Dr Maxey. We have looked at the role of IL-1, which seems to mimic the TNF results. However, our data with IL-1 and other cytokines are not yet complete. We are currently studying the bronchoalveolar lavage fluid and hope to publish more complete data correlating lavage fluid cytokine concentrations with direct physiologic changes observed during reperfusion. 